\title{
NOTA COMPLEMENTARIA AL TRABAJO "SEIS NOVEDADES DE LEGUMINOSAE-PAPILIONOIDEAE DE MÉXICO”
}

\author{
JERZY RZEDOWSKI \\ Instituto de Ecología, A.C. Centro Regional del Bajío \\ Apartado postal 386, 61600 Pátzcuaro, Michoacán, México \\ jerzy.rzedowski@inecol.edu.mx
}

En el número 110 de Acta Botanica Mexicana (pp. 1-19) se publicó el artículo intitulado "Seis novedades de Leguminosae-Papilionoideae de México", pero en su texto quedó incompleta la parte correspondiente a la descripción de la especie nueva Dalea estoraxana Rzed. \& Calderón, por lo que ésta no está cumpliendo con los requisitos del Código Internacional de Nomenclatura Botánica. En tal circunstancia se proporciona a continuación la información faltante.

\section{Dalea estoraxana Rzed. \& Calderón}

Frutex 1-1-5 m altus, (inflorescentia excepta) glaber; foliola (3)5 vel 7, elliptica, obovata vel oblanceolata, 5-18 mm longa, 2.5-6 mm lata, apice acuta vel rotundata; inflorescentiae oppositifoliae satis laxae, ad initium conicae, aetate cylindricae, 3-4(5) cm longae, 14-16 mm latae, 12-22 floribus; calyx 7-8 mm longus dense luteo-pilosus, glandulas nigras plurimas ferens: corola lutea, vexillium obcordiforme. ca. $4 \mathrm{~mm}$ longum, carina ca. $6.5 \mathrm{~mm}$ longa; stamina 8-10, ca. 10 mm longa.

Tipo: MÉXICO. Querétaro, cañón del río Estórax, cerca de El Plátano, municipio de San Joaquín, matorral submontano sobre laderas calizas y lutitas, alt. 900 m, 6.XII.1990, S. Zamudio y E. Carranza 8173 (holotipo IEB), isotipos por distribuirse.

Material adicional examinado: MÉXICO. Querétaro, cañón del río Estórax, entre El Plátano y Medias Coloradas, matorral submontano y bosque tropical caduc., lat. 2101'39", long. 99³0'54", 8.III.2000, L. Hernández 4533 (IEB); El Platano, rives et alentours du rio Estorax près El Platano, 850-900 m, lat. 20 $0^{\circ} 58^{\prime}$ 
$\mathrm{N}$, long. $99^{\circ} 37^{\prime} \mathrm{W}$, forêt tropicale caducifoliée, lithosol sur lutites, 3.X.1994, J.-N. Labat \& E. Carranza 2511 (IEB); cañon del río Estórax, entre El Plátano y Medias Coloradas, municipio de San Joaquín, laderas de rocas calizas con vegetación de matorral submontano y bosque tropical caducifolio, alt. $875 \mathrm{~m}, 7-8 . I I I .2000, S$. Zamudio y L. Hernández 11306 (IEB). 